\title{
Antibiotic Resistance in $E$. coli Isolated from Poultry
}

\author{
Ayushi Singh, Chhabra, Daljeet*, R. Sharda, S. Shukla, \\ Sachin D. Audarya, Ravi Sikrodia, R. Gangil and N. Singh
}

Department of Veterinary Microbiology, College of Veterinary Sc. and A.H., Mhow (M.P.), India

*Corresponding author

\section{A B S T R A C T}

Keywords

AST, Antibiotics, Mastitis

\section{Article Info}

Accepted:

04 September 2019

Available Online:

10 October 2019
A total of 150 samples from poultry were evaluated for avian pathogenic $E$. coli. All the 77 isolates of $E$. coli were tested for in vitro sensitivity towards 14 antibacterial drugs. The highest resistance was attributed towards antibiotic ampicillin, colistin, and nitrofurantoin followed by cefixime, cotrimoxazole, doxycycline, tetracycline, amoxyclav, ofloxacin, streptomycin, gentamicin, levofloxacin and amikacin. The highest sensitivity of $E$. coli was towards chloramphenicol antibiotic. Simultaneous resistance to 6 to 11 antibacterial agents was observed in all 77 (100\%) isolates.

\section{Introduction}

Escherichia coli have been the focus of immense international research after its recognition as a major cause of large scale epidemics of gastrointestinal illnesses in animals and man. Avian colibacillosis is the major disease in chicken which has been reported by several previous studies (Mellata, 2013; Matin et al., 2017; Subedi et al., 2018).

Antimicrobial therapy is an important tool in reducing both the incidence and mortality associated with avian colibacillosis. Commercialized poultry industries consume wide range of antibiotics for disease prevention and growth promotion. The antimicrobial use in the chicken is expected to rise by $129 \%$, by 2030 in the Asia-Pacific region (Tonu et al., 2011). However, the indiscriminate use is leading to wide spread antimicrobial resistance, which has received considerable National and International attention.

The development of resistance is a complex process associated with the presence of resistance encoding genes that are found inside plasmids or chromosomal genetic material. Integrons are the genetic material responsible for capturing resistance genes that spread via the genetic mobile elements; 
transposons and plasmid (Geidam et al., 2012).

\section{Materials and Methods}

A total number of 150 samples were collected from chickens, suspected for colibacillosis on post mortem, belonging to various organized farms and backyard poultry situated in and around Mhow and Indore cities. The presumptive isolation of bacterial isolates as E. coli was accomplished by colonial and bacterial morphology. Further, identification of bacterial isolates was done by both traditional methods and readymade kits (Hi media). Traditional biochemical tests were carried out as per procedure described by Barrow and Feltham (1993), Cheesbrough (1994) and Collee et al., (1996). Readymade Hi $E$. coli identification kits (Hi Media) were used for identification of isolates.

In vitro antibiotic sensitivity test (AST) of the isolates was conducted as per the method of Bauer et al., (1966). All the 77 isolates of $E$. coli were tested for in vitro sensitivity towards 14 antibacterial drugs viz. amikacin, amoxyclav, ampicillin, cefixime, chloramphenicol, co-trimoxazole, colistin, doxycycline, gentamicin, levofloxacin, nitrofurantoin, ofloxacin, streptomycin and tetracycline. The interpretation of result was made in accordance with the instruction supplied by manufacture.

\section{Results and Discussion}

All the 77 isolates of $E$. coli were tested for in vitro sensitivity towards 14 antibacterial drugs. These 14 antibiotics belonged to the nine groups viz. fluoroquinolones, aminoglycosides, tetracycline, cephalosporins, penicillin, nitrofuran, polymyxin, chloramphenicol and sulphonamide. Sensitivity of isolates to various drugs are summarized in Table 1.
E. coli isolates showed variable percentages of sensitivity and resistance to the different antibiotics.The highest sensitivity was attributed towards antibiotic chloramphenicol (71.42\%), amikacin (67.53\%), and gentamicin $(64.93 \%)$, followed by levofloxacin $(44.15 \%)$, tetracycline $(42.85 \%)$, ofloxacin $(16.88 \%)$, cotrimoxazole and $(9.09 \%)$, cefixime $(6.49 \%)$.

Only intermediate sensitivity was found against amoxyclav and streptomycin. The highest resistance $(100 \%)$ of E. coli was towards ampicillin, colistin and nitrofurantoin (Figure 1).

Variation in resistance and sensitivity percent has been found in various reports. Out of nine antibiotics tested, none of the antibiotic showed $100 \%$ resistance against the E. coli strains (Sharada et al., 2008; Subedi et al., 2018). Bakhshi et al., (2017) and Chaudhari et al., (2017) reported $100 \%$ sensitivity to antibiotic colistin, while, Qabajah and Ashhab (2012) reported $100 \%$ resistance against Tetracycline. These findings do not collaborate with the present findings. In our study, the highest percent of E. coli isolates were resistant to ampicillin and whereas lowest to amikacin, which is similar to the findings of Subedi et al., (2018). Also, cotrimoxazole and doxycycline, accounted more than $60 \%$ resistance among the tested $E$. coli isolates. These resistivity patterns of $E$. coli strains are comparable with the previous studies (Shrestha et al., 2011; Bakhshi et al., 2017; Magray et al., 2017; Manishimwe et al., 2017; Subedi et al., 2018).

Various antibiotics used for AST in this study have also been reported by others viz. Kim et al., (2007), Ogunleye et al., (2008), Sharada et al., (2008), Yadav (2010), Sahoo et al., (2012), Olarinmoye et al., (2013), Chaudhari et al., (2017) and Subedi et al., (2018). 
Table.1 Percentage sensitivity of E. coli isolates to different antimicrobial agents.

\begin{tabular}{|c|c|c|c|c|c|c|c|}
\hline \multirow{3}{*}{$\begin{array}{l}\text { S. } \\
\text { No. }\end{array}$} & \multirow[t]{3}{*}{ Antibiotics } & \multicolumn{6}{|c|}{ Total no. of isolates $(n=77)$} \\
\hline & & \multicolumn{2}{|c|}{ Sensitive } & \multicolumn{2}{|c|}{ Intermediate } & \multicolumn{2}{|c|}{ Resistant } \\
\hline & & No. & $\%$ & No. & $\%$ & No. & $\%$ \\
\hline 1. & Amikacin & 52 & 67.53 & 15 & 19.48 & 10 & 12.98 \\
\hline 2. & Amoxyclav & 0 & 0 & 36 & 46.75 & 41 & 53.24 \\
\hline 3. & Ampicillin & 0 & 0 & 0 & 0 & 77 & 100.00 \\
\hline 4. & Cefixime & 5 & 6.49 & 10 & 12.98 & 62 & 80.51 \\
\hline 5. & Chloramphenicol & 55 & 71.42 & 22 & 28.57 & 0 & 0.00 \\
\hline 6. & Colistin & 0 & 0 & 0 & 0 & 77 & 100.00 \\
\hline 7. & Co-trimoxazole & 7 & 9.09 & 14 & 18.18 & 56 & 72.72 \\
\hline 8. & Doxycycline & 5 & 6.49 & 23 & 29.87 & 49 & 63.63 \\
\hline 9. & Gentamicin & 50 & 64.93 & 12 & 15.58 & 15 & 19.48 \\
\hline 10 & Nitrofurantoin & 0 & 0 & 0 & 0 & 77 & 100.00 \\
\hline 11. & Levofloxacin & 34 & 44.15 & 31 & 40.25 & 12 & 15.58 \\
\hline 12. & Ofloxacin & 13 & 16.88 & 25 & 32.46 & 39 & 50.64 \\
\hline 13. & Streptomycin & 0 & 0 & 53 & 68.83 & 24 & 31.16 \\
\hline 14. & Tetracycline & 33 & 42.85 & 0 & 0 & 44 & 57.14 \\
\hline
\end{tabular}

Table.2 Multiple drug resistance in E. coli isolates.

\begin{tabular}{|l|c|c|c|}
\hline S. No. & No. of antibiotics & No. of resistant isolates & Percent of resistant isolates $(\mathbf{n}=\mathbf{7 7})$ \\
\hline $\mathbf{1 .}$ & 6 & 15 & 19.48 \\
\hline $\mathbf{2 .}$ & 7 & 29 & 37.66 \\
\hline $\mathbf{3 .}$ & 8 & 17 & 22.07 \\
\hline $\mathbf{4 .}$ & 9 & 11 & 14.28 \\
\hline $\mathbf{5 .}$ & 11 & 5 & 6.49 \\
\hline
\end{tabular}

Fig.1 Percentage sensitivity of $E$. coli isolates to different antimicrobial agents.

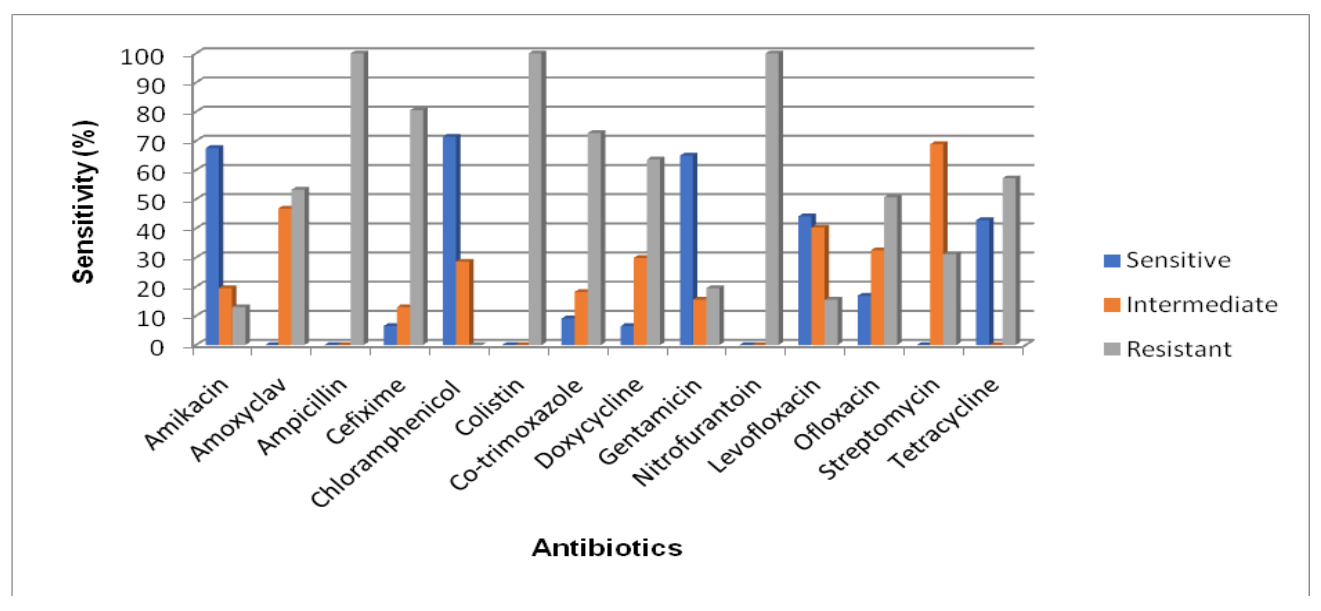


Fig.2 Multiple drug resistance in E. coli isolates.

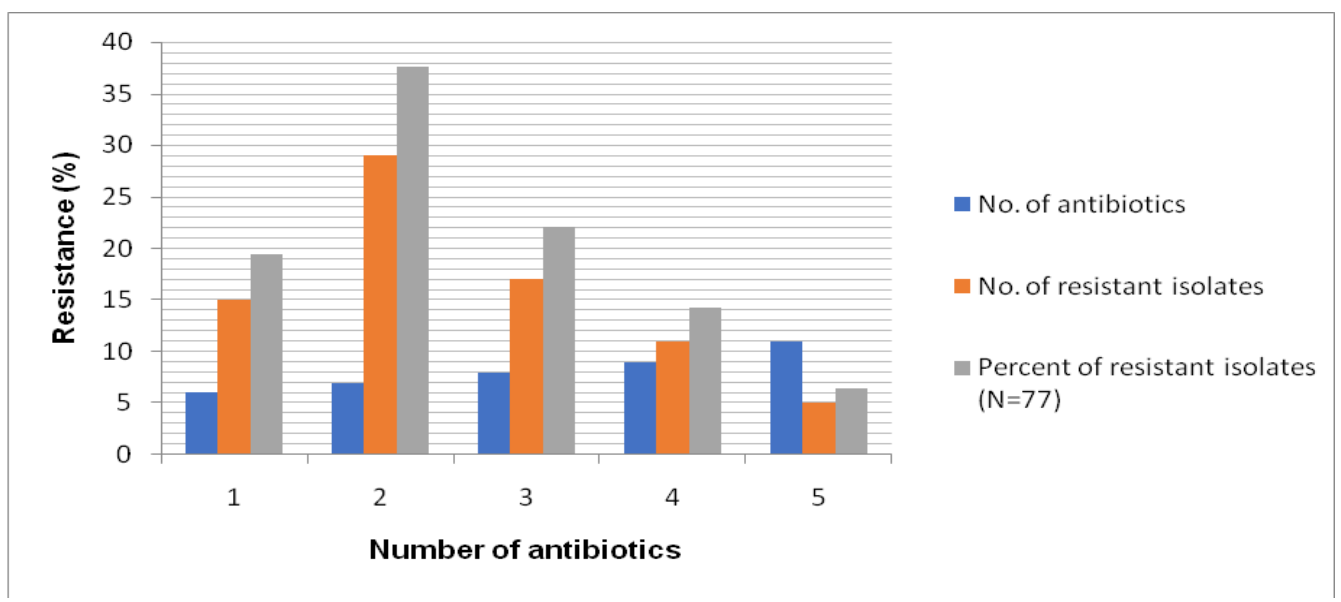

\section{Multi drug resistance}

Multiple drug resistance to 6 to 11 antibacterial agents simultaneously was observed in all isolates (Table 2). The maximum (37.66\%) isolates were resistant to 7 drugs (Figure 2). None of the isolate was resistant to all the 14 antimicrobial agents.

Multi drug resistance against was also reported by Manishimwe et al., (2017), Amer et al., (2018) and Subedi et al., (2018).

The results of this study are in variance with the findings of other workers, indicating that antibiotic sensitivity pattern varies with different isolates, time and development of multiple drug resistance among different $E$. coli isolates related to transmissible $\mathrm{R}$ factor/ plasmid.

Selection pressure for the development of MDR plasmids in the gut flora of birds is driven by the routine addition of antibiotics to poultry feed and water for disease prevention and growth promotion (Bager et al., 1997; Van den Bogaard and Stobberingh, 1999).

The usage of antibiotics correlates with the emergence and maintenance of antibiotic resistant traits within pathogenic strains. These traits are coded by particular genes that may be carried on the bacterial chromosome, plasmids, transposones or on gene cassettes that are incorporated into integrons (Daka et al., 2012) thus are easily transferred among isolates. The transmission of resistance plasmids of $E$. coli from poultry to human have also been reported (Maansouri and Shareifi, 2002).

The level of resistance of organism to a particular drug might be due to the indiscriminate use of the respective drugs. Hence, antibiotic should be used at recommended dosage for appropriate time course preferably after performing the in vitro sensitivity testing.

The antibiotic resistant patterns found in this study suggest a serious situation of prevalence of the antibiotic resistant $E$. coli strains among broiler chickens.

\section{References}

Amer, M.M., Mekky, H.M., Amer, A.M. and Fedawy, H.S. (2018). Antimicrobial resistance genes in pathogenic Escherichia coli isolated from diseased broiler chickens in Egypt and their relationship with the phenotypic 
resistance characteristics, Veterinary World, 11(8): 1082-1088.

Bager, F., Madsen, M., Christensen, J. and Aarestrup, F. M. (1997). Avoparcin used as a growth promoter is associated with the occurrence of vancomycin-resistant Enterococcus faecium on Danish poultry and pig farms. Preventive Veterinary Medicine, 31(1-2): 95-112.

Bakhshi, M., Bafghi, M.F., Astani, A., Ranjbar, V.R., Zandi, H. and Vakili, M. (2017) Antimicrobial resistence pattern of Escherichia coli isolated from chickens with colibacillosis in Yazd, Iran. Journal of Food Quality and Hazards Control, 4: 74-78.

Barrow, G.I. and Feltham, R.K.A. (1993). Cowan and Steel's manual for the identification of medical bacteria, $3^{\text {rd }}$ edn. Cambridge University Press, Cambridge. pp 140-143.

Bauer, A.W., Kirby, W.M.M., Sherris, J.S., and Turk,M. (1966). Antibiotic susceptibility testing by a standard single disc method. American Journal of clinical Pathology, 45: 493-496.

Chaudhari, S.V., Joshi, B.P., Desai, D.N., Bhanderi, B.B., Choudhary, K.R. and Madhwal, A. (2017). Isolation and characterisation of $E$. coli infection from the bronchial plug of broiler birds associated with respiratory diseases. Advances in Animal and Veterinary Sciences, 5(8): 334.

Cheesbrough, M. (1994). Medical Laboratory Manual for Tropical Countries. $1^{\text {st }}$ edn. Vol.II, E.L.B.S. and Butterworth and Co. Ltd., Kent. pp 401-404.

Collee, J.G., Fraser, A.G., Marion, B.P. and Simmons, A. (1996). Mackie and McCartney's Practical Medical Microbiology, $4^{\text {th }}$ edn. Churchill Livingstone, New York.

Daka, D., Silassie, S.G. and Yihdego, D. (2012).

Antibiotic-resistance
Staphylococcus aureus isolated from cow's milk in the Hawassa area, South Ethiopia. Annals of Clinical Microbiology and Antimicrobials, 11: 26.

Geidam, Y.A., Ambali, A.G. and Onyeyili, P.A. (2012). Detection and antibiotic sensitivity pattern of avian pathogenic Escherichia coli strains among rural chickens in the arid region of Northeastern Nigeria. Veterinary World, 5(6): 325-329.

Kim, T.E., Jeong, Y.W., Cho, S.H., Kim, S.J. and Kwon, H.J. (2007). Chronological study of antibiotic resistances and their relevant genes in Korean avian pathogenic Escherichia coli Isolates. Journal of Clinical Microbiology, 45(10): 3309-3315.

Magray, S.N., Wani, S.A., Kashoo, Z.A., Bhat, M.A., Adil, S., Farooq, S., Rather, M.A., Kabli, Z.A., Banday, M.T. and Nishikawa, Y. (2018). Serological diversity, molecular characterisation and antimicrobial sensitivity of avian pathogenic Escherichia coli (APEC) isolates from broiler chickens in Kashmir, India. Animal Production Science, 59(2): 338-346.

Manishimwe, R., Buhire, M., Uyisunze, A., Turikumwenayo, J.B. and Tukei, M. (2017). Characterization of antibiotic resistant Escherichia coli in different poultry farming systems in the Eastern Province and Kigali City of Rwanda. Revue D'elevage Et De Medecine Veterinaire Des Pays Tropicaux, 70(1): 13-19.

Mansouri, S. and Shareifi, S. (2002). Antimicrobial resistance pattern of Escherichia coli causing urinary tract infections and that of human fecal flora in the southeast of Iran. Microbial Drug Resistance, 8: 123-128.

Matin, M.A., Islam, M.A. and Khatun, M.M. 
(2017). Prevalence of colibacillosis in chickens in greater Mymensingh district of Bangladesh. Veterinary World, 10(1): 29-33.

Mellata, M. (2013). Human and avian extraintestinal pathogenic Escherichia coli: infections, zoonotic risks, and antibiotic resistance trends. Foodborne Pathogens and Disease, 10: 916-32.

Ogunleye, A.O., Oyekunle, M.A. and Sonibare, A.O. (2008). Multidrug resistant Escherichia coli isolates of poultry origin in Abeokuta, South Western Nigeria. Veterinarski Arhiv, 78(6): 501-509.

Olarinmoye, A.O., Oladele, O.O., Adediji, A.A., Ntiwunka. and Tayo, G.O. (2013). Antibiograms of avian pathogenic Escherichia coli isolates from commercial layers with colibacillosis in southwest Nigeria. Malaysian Journal of Microbiology, 9(4): 317-325.

Qabajah, Q. and Ashhab, Y. (2012). Avian pathogenic Escherichia coli (APEC) in Palestine: Characterization of virulence factors and antibiotic resistance profile. Veterinary Research, 30(2-3): 299-316.

Sahoo, T.K., Sahoo, L., Sarangi, L.N. and Panda, S.K. (2012). Prevalence, isolation, characterization and antibiogram study of pathogenic Escherichia coli from different poultry farms of Odisha. Journal of Advanced
Veterinary Research, 2: 169-172.

Sharada, R., Ruban, S. and Thiyageeswaran, M. (2008). Antibiotic resistance pattern of Escherichia coli isolated from poultry in Bangalore. The Internet Journal of Microbiology, 7(1): 1-5.

Shrestha, E.K., Dhakal, I.P., Sapkota, M., Manandhar, P. and Rijal, T.B. (2011). Antimicrobial resistance pattern of Eshcerichia coli isolates from chicken and human samples in Chitwan. Nepalese Veterinary Journal, 30: 3844.

Subedi, M., Luitel, H., Devkota, B., Bhattarai, R.K., Phuyal, S., Panthi, P., Shrestha, A. and Chaudhary, D.K. (2018). Antibiotic resistance pattern and virulence genes content in avian pathogenic Escherichia coli (APEC) from broiler chickens in Chitwan, Nepal. BMC Veterinary Research, 14:113.

Tonu, N.S., Sufian, M.A., Sarker, S., Kamal, M.M., Rahman, M.H. and Hossain, M.M. (2011). Pathological study on colibacillosis in chickens and detection of Escherichia coli by PCR. Bangladesh Journal of Veterinary Medicine, 9: 17-25.

Van den Bogaard, A.E. and Stobberingh, E.E. (1999). Antibiotic usage in animals: Impact on bacterial resistance and public health. Drugs, 58: 589-607.

\section{How to cite this article:}

Ayushi Singh, Chhabra, Daljeet, R. Sharda, S. Shukla, Sachin D. Audarya, Ravi Sikrodia, R. Gangil and Singh, N. 2019. Antibiotic Resistance in E. coli Isolated from Poultry. Int.J.Curr.Microbiol.App.Sci. 8(10): 89-94. doi: https://doi.org/10.20546/ijcmas.2019.810.010 